\title{
Promoting Dialogic Pedagogy through Restricting Technologies
}

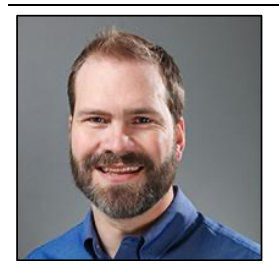

Darren Dyck

Ambrose University, Canada

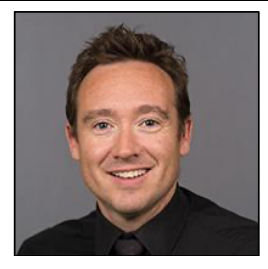

James (Jim) Cresswell

Ambrose University, Canada

\begin{abstract}
This commentary responds to claims Eugene Matusov makes about a student's right to the use of certain technologies in his or her education. We argue that the use, in particular, of adaptive technologies actually has the potential to inhibit a student's free choice (rather than facilitate it) and that through restricting certain technologies, genuine dialogic pedagogy may more successfully be promoted. We also engage Matusov's concept of the radical freedom necessary for education.
\end{abstract}

Darren Dyck is an Assistant Professor of English at Ambrose University. His primary areas of expertise are Shakespeare and Renaissance literature, but he writes and teaches on a variety of subjects, including ancient and medieval literature, the works of J.R.R. Tolkien and the Inklings, and contemporary higher education. He also tweets @ambrose_en_prof.

James (Jim) Cresswell is a full professor from Ambrose University. Theoretically, he is inspired by Bakhtin and dialogism. The theory inspires community-based research aimed at using research to support community organizations. Other areas of interest include: poverty; theoretical, historical, and philosophical psychology; cognitive science of religion; and immigration. He has a deep commitment to education and enhancing the student experience. He has won numerous awards, spoken at international events, and published a substantial amount. Currently, he serves as a Deputy Editor at Dialogic Pedagogy, Editor for the Journal of Theoretical and Philosophical Psychology, and sits on the editorial board of Theory and Psychology.

\section{2बS}

\section{Introduction}

In January 2019, we (Darren Dyck, James Cresswell) began teaching one course each in which we attempted to remove some forms of digital technology from our students' pedagogical milieu. In particular, we prohibited students from communicating with us via email, except in rare circumstances (e.g. medical emergencies, student accessibility accommodations), and we took measures to eliminate PowerPoint from the classroom. Further, we did not provide any course materials to students using the online learning management system (LMS)—materials, in other words, which they could access at their leisure-or allow them to use the LMS to submit assignments digitally. We did not, to be clear, stop students from using their own technological devices (laptop computers, tablets, smart phones, etc.) as this seemed to us a clear infringement on certain freedoms they enjoy, but we did strongly encourage them to use hard copies of textbooks, paper, and pens or pencils when in class. 
Darren's class was a second-year undergraduate course called Popular Fiction, in which students read a number of works of fiction (short and long) that don't typically get taught in university English programs because they're deemed not literary enough or, if you like, "genre." We read detective, science fiction, science fantasy, western, and horror texts. There were about 18 students in the class, about half of which were English majors, and what happened in the classroom varied from class to class. Sometimes I (Darren) lectured, sometimes there was discussion, once we engaged in creative group work, and a couple of times we had other faculty join us for a conversation. Ultimately, the goals of the course were to familiarize students with fiction in the genres mentioned above, to teach critical reading and writing skills, and to have students interrogate (to some degree) the categories of "literary" and "popular" fiction.

James' class was a third-year undergraduate class on the Psychology of Religious Experience. It looks at texts over the last 100 years: James (Varieties of Religious Experience); Freud (Future of an Illusion); Maslow (Religions, Values, and Peak Experiences); Barrett (Why Would Anyone Believe in God). The class is a seminar class that is quite unstructured (e.g., I, James, collect index cards at the beginning of class about the assigned reading and the cards contain concepts/ideas from the readings that the students want to discuss). It is capped to around 25 students. The focus is about being able to think through the different perspectives of the authors and then to reflect on one's own spiritual experience (broadly conceived). The students are usually upper year undergraduate students in the social sciences, and I get a few theology/ministry students taking it as an elective. A number of them come from religious backgrounds, but not all. The class is reasonably diverse.

James Cresswell shared our rationale for removing some forms of digital technology from our students' pedagogical milieu (which we also provided to our students in our syllabi) on the Dialogic Pedagogy Journal Facebook page, which, in part, prompted Eugene Matusov to write "A student's right to freedom of education." While Matusov does slightly mischaracterize our actions in his paper's acknowledgements, his argument nonetheless stands in opposition to some of the pedagogical ideas motivating these actions. What follows, therefore, responds both to (1) our sense of Matusov's critique of our actions and their implications for a student's right to freedom of education, as well as to (2) more fundamental claims he makes about the nature of education and the essentiality of freedom for it. ${ }^{1}$

We argue, in particular, that because technology has in recent years undergone such a fundamental metamorphosis, it is no longer possible (if it ever was) for educators to view it simply in terms of what we or our students would make of it. Technology has always been integrated with our thinking, perhaps especially so in educational contexts, but now certain adaptive technologies may create more problems for students than they solve; to put this in Matusov's terms, it's possible certain technologies readily embraced by both educators and students actually infringe upon the freedom of education which, he maintains, students are entitled to, more than they facilitate it. It is our contention that Matusov's failure to account for this possibility arises, in part, from the conception of radical freedom of education he espouses. Such a conception, we think, not only relies on certain unsubstantiated assumptions he makes about students' free agency, it denigrates expertise, devalues (and thus disregards) a number of potentially positive educational outcomes, and ultimately makes it harder for students to experience genuine dialogic education.

\footnotetext{
${ }^{1}$ The great irony of our attempts to remove some forms of technology from our students' pedagogical milieu is that because of the COVID-19 pandemic, we were forced to jettison our approach entirely and conduct the last five weeks of our courses by relying exclusively on digital and web-based technologies.
} 


\section{A Student's Right to Freedom of Education}

Matusov's fundamental claim is that students should be free to "define their own education" ( $p$. SF2). According to the principles for a student's right to freedom of education enumerated in his paper ( $p$. SF10 and following), a student's freedom extends into all realms of learning, including the curricular, instructional, valuative, and ecological (among others). The principles of instructional and ecological freedom, in particular, seem to entail that students should be able to determine for themselves what role(s) technologies might play in their learning. As Matusov writes, "learning activities cannot be imposed on the student but only offered" ( $p$. SF12), and certainly by learning activities he includes those enabled by technological means. He asserts, additionally, that "a teacher can develop a list of possible diverse, rich learning activities and projects that the student can choose from, modify, or amend with their own" ( $p$. SF12), and here, again, the implication is that instructors genuinely committed to a student's right to freedom of education are obliged not only to offer but to develop such learning activities and projects as they are able given the technologies available. In delineating students' rights to ecological freedom, Matusov argues that students require "access to diverse, rich, and safe resources" (p. SF13), and these may include, according to the example of an afterschool program he cites in his paper, a "computer room" (p. SF13) where learners, free to define the terms of their own education, can play video games.

Central to Matusov's conception of a student's right to freedom of education is choice-not simply the ability to choose (a subject we'll return to later) but the number or 'diversity' of choices offered to students by instructors. As he suggests by way of his discussion of the "curricular map," which he provides students at the beginning of his courses and which offers potential avenues for their learning to take $(p$. SF11), the greatest variety seems to entail the greatest freedom. Even if a student chooses a path of his or her own, one not offered by the curricular map, or, ultimately, not to engage in the learning process at all, it is incumbent upon educators to provide choice. As there are already inescapable and circumstantial limits placed on students' abilities to freely define their own education, Matusov naturally sees the additional limits placed by us on our students as an unethical infringement upon their right-this being the case regardless of the rationale for our actions.

We, however, would like to maintain that our decision to remove certain forms of digital technology from our students' pedagogical milieu was not only ethically motivated but a decision made in light of an ontological commitment that privileges dialogue and, ultimately, has students' freedom as its aim. We simply think that the use of certain technologies makes dialogue harder, and thus the aim of freedom more difficult to achieve.

\section{Technology and Education}

It is not really surprising that the use of certain technologies can subvert the aims of those who use them. Neil Postman (1993) argued that technologies can only naively be thought of as tools unproblematically subject to their users' desires for them. In Technopoly, he cites the myth of Theuth and Thamus (presented by Plato in the Phaedrus): Theuth is an inventor credited with the establishment of, among other things, arithmetic and geometry, and he brings to Thamus, a wise king, his newest invention: the written word. Theuth tells Thamus that the people who employ this new technology will benefit by becoming both wiser and having better memories. Thamus, though, suggests that Theuth is too fond of his own invention to see objectively and reveals that the use of this particular technology will actually have the opposite of Theuth's desired effect: it will prompt forgetfulness in learners because "they will rely on writing to bring things to their remembrance by external signs instead of by their own internal resources," and they will "receive a quantity of information without proper instruction, and in consequence be thought very knowledgeable when they are for the most part quite ignorant" (Plato, p. 96; qtd. in Postman, p. 4). Of 
course, pedagogues' concerns with technologies are not new, but we argue below that there is a current qualitative shift that makes current discussions about technology unique.

Perhaps the most surprising thing about Postman's thoughts on the "surrender of culture to technology" (his book's subtitle) is that he first offered them in 1992, just before the rise of the technologies we're highlighting below as "adaptive." Also writing in 1992 with a similar capacity for foresight was Albert Borgmann. In Crossing the Postmodern Divide, Borgmann spoke about a qualitative shift in the nature of technology (especially as it relates to humans) and the resultant advent of what he calls "a technologically sophisticated and glamorously unreal universe, distinguished by its hyperreality, hyperactivity, and hyperintelligence" (p. 6).

Hyperintelligence, Borgmann argues, relates to the extension of human minds through integration with the processing and storage capacities of computers. Such integration enables humans to grapple with more, cognitively speaking, and, not surprisingly, their enhanced ability to process information engenders a faster pace of life, which in turn propels humans into hyperactivity. At the same time, human minds, despite having technologically enhanced abilities, actually grapple with less and less of reality, as "processors" provide enhanced and augmented representations of reality-a hyperreality that overcomes and replaces tangible reality, which, according to Borgmann, is "dirty and interminably ambiguous" and "moves at the deliberate pace of daily, seasonal, and generation rhythms" (p. 100). Hyperreality, by contrast, is a refined technologically mediated simulacrum that "can be played at any time" (p. 100). As humans become increasingly integrated with and shaped by their engagement with hyperreality, technologies become more adaptive, more responsive to the new desires and ways of thinking produced by this intermingling of mind and tech.

In some ways, both Postman's and Borgmann's concerns seem like profound understatements given the technological milieu in which we find ourselves today. Popular writers such as Tristan Harris (n.d.) and Jaron Lanier (2018), former tech industry insiders, write about the way application developers structure our experience in such a way as to maximize what the tech industry calls 'engagement' (basically, time spent on an application). Further, according to Wu (2017) and Alter (2018), applications are designed to produce pleasure in order to harvest the most valuable resource we have: our attention. Attention provides a stream of data that can be sold to advertisers and used to manipulate our desires. Lanier writes about Instagram, for example, tracking the dilation of users' pupils and the flush of their cheeks to learn what can be presented to keep people engaged with the application. Snapchat tracks use in order to anticipate when people will become bored with the application and then sends notes to users that preempt their decision to take time away from the software. Facebook algorithms customize the information presented in a way that creates a filter bubble, stimulating emotions which prompt us to stay in the application. Unlike, say, the technology of the alarm clock that goes off at 6:00 am regardless of one's desire to sleep in, our current technological milieu is uniquely demarcated by being increasingly hyperreal and adaptive. ${ }^{2}$

Two consequences of hyperrealism, according to Borgmann, seem relevant for our purposes here: sullenness and methodological universalism. Sullenness is produced when, having been compelled by the comparative untidiness and dullness of life to retreat into hyperreality (and thus isolation), people experience indolence at the prospect of ever coming to terms with the excess of information available to them. This ultimately leaves them lacking both concern for complexity and the tenacity required to pursue certain personal enterprises. Interestingly, Borgmann predicted not only the erosion of self-discipline we see emergent in many students, but also the self-righteousness that manifests in assertions like 'it's my choice' or 'I'm free to do what I want.' These may sound like indicators of responsibility, but they actually

\footnotetext{
${ }^{2}$ The example of the alarm clock, as will become clear later in this paper, is itself not entirely unproblematic.
} 
express a sullen retreat from life amounting to a "refusal to discuss, explain, and justify a decision" (p. 10). Communal ties in hyperreality become burdensome and dialogue almost impossible. Methodological universalism insists upon the primacy of method in learning, which means that education becomes not about what is learned (i.e. substance) but, rather, the universally applicable need to rank or measure. To put it another way, hyperreality engenders a pedagogical milieu in which it makes less sense to ask if one has learned something than it does if there is a suitable token that may be taken to signify educational success. Further, methodological universalism accords with a fragmentary approach to information where what is known is by necessity abstracted or divorced from context and life.

To turn to our situation: while it would seem that the ability to email their instructors, to learn (at times) via PowerPoint, and to access information or course materials through the LMS could only benefit students, we think that each of the above technologies not only participates in but perpetuates our hyperreal pedagogical milieu and, in various ways, disinclines students from the embodied communication essential for dialogic education.

Email has the potential to direct both educators and learners away from rather than toward dialogue and the complexities it invites. I myself (DD) regularly receive email communications from students offering me a thought-often a tentative thesis statement for a paper-and then prompting me to respond in one of two ways: either yes, this is a good thought, or no, this is not a good thought. And despite my attempts to respond in nuanced ways (neither yes nor no), students tend to interpret any response other than a clear and definitive yes as negative. This perceived negative response is, for many students, alienating. The reasons for this are various, but certainly email itself might be seen as, first, encouraging simple-minded or categorically-reductive thinking, and second, by training students to expect answers that conform to their desires, prompting both their perception of rejection and the subsequent alienation they experience. ${ }^{3}$

Additionally, email technology creates a pedagogical milieu that absents addressees from the consideration of senders. The student who sends an email asking for (and thus expecting) a particular kind of response either disregards the addressee or abstracts them from their embodied existence. ${ }^{4}$ Email, like other technologies, is unnaturally-inhumanely, we might say—static: the addressee is always the samename@emailaddress.domain-even though the person receiving the emails changes from moment to moment, depending on context, mood, thoughts, etc. Finally, the accessibility and immediacy of email trains both educators and learners to treat addressees as though they, too, were always accessible and ought to be immediately responsive-treats them, in other words, not as humans but as the technologies with which they are increasingly integrated.

PowerPoint is also emblematic of our hyperreal pedagogical milieu. Indeed, instructors are strongly encouraged to use the software just by virtue of the fact that it is (almost without exception) provided to them by their institutions; it is an integral part of their intellectual world. Instructors are thus trained by a technology that by its very nature breaks things down into individual units to reduce their knowledge into easily consumable bullet-points. And these bullet-points, in turn, encourage students to anticipate knowledge being transmitted to them in a fragmentary way, disconnected from the whole. Though Borgmann had no knowledge of PowerPoint technology, his claim that method would replace substance is, here, very much on display (pun intended). We see, too, the real, embodied educator absented-become

\footnotetext{
${ }^{3}$ Certainly, this alienation we identify is related to Borgmann's concept of sullenness, which is characterized by the same kind of withdrawal from dialogic engagement I have observed in students.

${ }^{4}$ We see an extreme example of this phenomenon of absent addressees in the comments sections of popular news stories; there, readers, having very little sense or awareness of the people they're addressing (either the writer of the article or, perhaps, subjects mentioned in the article), feel unnaturally free to express their vilest and hateful thoughts. They become disassociated from the human connections that underscore all ethical relationships.
} 
the abstraction of a bright and seductive screen, which has itself become the measure of what's significant or meaningful. But the seduction is not simply visual: PowerPoint invites learners to desire a form of education that is disengaged from others (and thus comfortable) and entices them into thinking that learning occurs primarily in terms of the hyperreal (for these bullet-points often have little observable connection to their everyday experiences).

Learning management systems likewise become, in students' minds, abstracted or distantiated versions of their instructors (or, in some cases, a given author being read in a course). If life is dirty, ambiguous, and slow, then the LMS offers an appealing alternative. Here, instructors can post their messages to students, PowerPoint slides, assignments, rubrics, and other course materials; and students can access these at their leisure, whenever they desire it. Like email and PowerPoint, the LMS has the effect of training students to conceive of their instructors in the same terms they use to think about the technologies they employ, in Borgmann's sense, as dispensable resources, able to be accessed with ease, but also, and more problematically, without much in the way of ethical obligation. A student misplaces his syllabus for a given course and, unable (for whatever reason) to access a digital version from the course's LMS, transfers his expectation onto the instructor. Or, a student clicks the "completed" boxes for her assignments and thinks, as a result, she has done all her instructor desires her to do. It hardly needs to be said that the accessibility and reward of such a system are features designed, as those of Instagram, Twitter, Facebook, to keep students engaged. A question, though, is engaged with what exactly?

Email, PowerPoint, and LMS technology may have the potential to be useful dialogic tools, but because they tend to create and feed particular kinds of desires and ways of thinking (in both learners and educators), they typically reduce opportunities for actual dialogic education rather than increase them. For students who have grown up surrounded by such adaptive technologies, to, say, email a professor with the intention of seeking dialogue requires a singular resistance to the tendencies of the medium itself. Dialogue is already hard, so by allowing email to be a primary means of communication between educators and learners, we're essentially asking those learners to do one thing when being passively encouraged by the medium to do another. Additionally, having been habituated to certain technologies—having, in other words, had their thinking inextricably integrated with their environment-students may not actually be capable of enjoying a free relationship to technology. In his popular book The Shallows, Nicholas Carr (2011) offers a good illustration of technology integrating with the performance of psychology: the invention of the clock. Prior to the existence of the clock, humans thought differently about time. Activities were not conceived of in terms of duration and rendezvous, for example, were not understood as occurring at fixed points in time. Humans' entire way of thinking about the movement of life throughout the day was completely different. Technologies are integrated with human thinking, and so psychological activities like learning in a classroom are integrated with the technological milieu in which we all find ourselves. Postman would argue that students are decidedly not free to think about time in the way that people prior to the clock's invention did.

Central to Dialogic Pedagogy is the notion of dialogue rooted in the Bakhtinian tradition. Life is polyphonic — there is never a single voice expressed in a given utterance-and Bakhtin, not surprisingly, is critical of attempts to be monologic. Matusov picks up on Bakhtin's emphasis on freedom from monologic tendencies in education and, consequently, embraces variety and students' freedom of choice as a means to disrupt these tendencies - to create the loopholes and parodies that prevent and subvert the hegemony of monologic utterances. There is a logic to his embracing of these, but also, as we hope we're showing, a lack of consideration for both adaptive technology's tendency to inhibit educators' attempts to disrupt such monologic utterances and the fact (which will be discussed below) that dialogue requires more than simply freedom. Indeed, our decision to remove some forms of technology from our students' pedagogical milieu- 
technologies we recognize as creating a certain uniformity of desire and thought in students, as well as a disinclination to dialogue-is an attempt to engineer a so-called rupture. We sought to push back against the alienation characterizing our students - an alienation many are entirely unaware of-and offer them a genuine experience of embodied dialogic education. Matusov privileges student desire in advocating for a student's right to free education, but his insistence on radical freedom relies on the assumption that students are actually free to choose. Such a freedom would seem to entail, among other things, students' free relationship with technology, but this, as we have suggested, is problematic. Indeed, we might say that Matusov's whole conception of students' freedom to choose needs to be reconsidered.

\section{Matusov's Radical Freedom}

Matusov eschews all notions of instrumentality in education. One of the consequences of his position is that educator-determined outcomes become untenable, for in order to ensure a given outcome is fulfilled an instructor must by necessity make impositions on his or her students, whether these be curricular, valuative, ecological, or what have you. And, to reiterate, Matusov insists that students "must have the exclusive right to freely define their own education" (p. SF2).

We return to this familiar refrain because it bears thinking about where the legitimacy of students' exclusive right comes from. What is it, specifically, that enables them to choose the course their education takes? From what does their authority - their ability to 'author' their own education-derive? While these may seem like questions posed in jest, there are at least two potential answers suggested by Matusov that ought to be considered. The first is that students' right to define the terms of their own education doesn't derive from expertise.

Matusov is very clear that not having knowledge in, say, a given field shouldn't disqualify students from choosing the course of their own education. Indeed, he claims that instructors are often tempted to foist their own educational agenda on students in view of their ignorance, and that those who succumb to this temptation fail in their educational mandate; they effectively "table" their students "educational desires [...] until [...] school is over" (p. SF11). It is crucial to education, he insists, not to position students as objects but, instead, to facilitate their role as subjects of education. Matusov goes so far as to suggest that "when the teacher selects and imposes the material that the student must learn to master and transcend, the teacher severely curtails the student's creativity" and consequently "either destroy[s] or severely damage[s] their creative self-expression" (pp. SF7-SF8). This, in Matusov's terms, is "pedagogical violence" (p. SF6).

We will return to the notion of pedagogical violence but, first, would like to consider Matusov's reference, here, to "self-expression." This term points us, again, to the question of what legitimates students' exclusive right to freely define their education. If the answer is not expertise, then it can only be some thing already in their possession, something which can be expressed. It is, again, not our desire to be playful or vague, but Matusov is not at all clear about what this thing is, about what legitimates students' intrinsic right to freedom of education or, more to the point, what enables them to so freely define their education. From Matusov's perspective, students simply have it, and imposed outcomes, like attempts to make "people [...] good through education," ultimately "strip people of their agency to make their own moral choices" (p. SF6).

Our contention, to put it another way, is that Matusov assumes, problematically, that students de facto have freedom, that they are, even before they formally enter into an educational context, capable of choosing the course or defining freely the terms of their own education. We've already tried to illustrate in our discussion of email, PowerPoint, and LMS technology that this is in no way a given. What if students, we would like to ask, aren't free, and our removal of certain technologies serves to free them, if only a little? 
Matusov writes that if a student doesn't take ownership of his own education, he will act "like a zombie [...] without much spirit" (p. SF8), but (to borrow his metaphor) what if students enter our classrooms already zombiefied?

The difference between Matusov's conception of freedom in education and ours should now be patent: whereas he thinks freedom is essential to education-for example, all of the educational paradigms he outlines "need a student's freedom" (p. SF3, emphasis added)-we think freedom is more appropriately thought of as the end of education. A consequence of our position is that, while freedom is always a factor in education, it's inevitably a limited rather than a "radical" freedom. Certainly Socrates, an emblem of dialogic education, not only exercised power over many of his interlocutors and sought to use that power for his own educational aims (i.e. outcomes), he engaged with others relying on an assumed epistemology and ontology. Matusov's characterization of the education paradigm of critical examination, wherein "[a]ny construction of knowledge [...] is by-productive" (p. SF4), would be entirely foreign to Socrates, for his goal was ever to move those he spoke with closer to a knowledge of the Good, which would, in turn, free them.

Matusov's characterization of radical freedom in education requires him to make a number of seemingly all-or-nothing type of statements. He says, for example, in his discussion of the training educational paradigm, that "foisted" education is "often irrelevant, insensitive, and not very motivating" ( $p$. SF10). What is the basis of such a claim? Our response to the problem of technology is to enable dialogue that is simply relevant, sensitive, and motivating. Wouldn't it rather be the case that the bulk of the content students receive in educational training is about paradigmatic situations that are quite relevant, but nevertheless seemingly irrelevant in their dirty and slow realism?

Even more egregious are the assumptions Matusov makes about what can and can't be meaningful to students. He says, in the "Rebukes to Objections" section of his paper, that "without a student actively raising a question important for the student, their teacher's answer usually remains meaningless for the student" (p. SF19). Again, usually meaningless? Or, as is implied, lacking entirely in meaning? Isn't it possible for students to adopt the ideas of their instructors about what is meaningful, at least to some degree? Can students respond only with slavish obedience when imposed upon by their instructors? Isn't it conceivable that students could oscillate between being objects and subjects of education, and learn from this very oscillation, this intermittent inequality? Finally, when Matusov, at the end of his paper, suggests that "a teacher can legitimately [...] expose the students to alternative ideas and activities [and] challenge the students' dear ideas and beliefs (at the students' consent)" (p. SF15), isn't it a very fine line between "impose" and "expose"? As we've already suggested, given the potential difficulty of freely defining the terms of their own education, isn't the "consent" students give in this scenario highly problematic? It's not like the consequences of a given educational choice can be easily explained to students who haven't yet developed the critical vocabulary to understand that choice or consider its consequences.

Ultimately, our decision to remove some digital technologies from our students' pedagogical milieu was founded upon a desire to create a rupture in the flow of what we see as their alienated praxis. (Such a rupture may well create student agency where it previously didn't exist.) We wanted them to have a genuine educational experience of real dialogue. But dialogue, in our view, involves not just freedom (as Matusov insists) but an ontological given. When Bakhtin writes about dialogue requiring "embodied meanings" that must come into "inner contact," he is drawing attention to a certain ontological weightiness (see Cresswell \& Sullivan, 2019), to the fact that in dialogue something important is always at stake. Bakhtin writes:

The weakening or destruction of a monologic context occurs only when there is a coming together of two utterances equally and directly oriented toward a referential object. Two discourses equally and directly 
oriented toward a referential object within the limits of a single context cannot exist side by side without intersecting dialogically, regardless of whether they confirm, mutually supplement, or (conversely) contradict one another, or find themselves in some other dialogic relationship (that of question and answer, for example). [...] Two embodied meanings cannot lie side by side like two objects - they must come into inner contact; that is, they must enter into a semantic bond. (1984a, pp. 188-189, emphasis added).

The notion of a "referential object" may seem like a curious idea given that Bakhtin is well known to espouse a dialogical approach to epistemology that precludes naïve realism. His discussion of embodiment in the case of Rabelais (1984b), his early aesthetics (1990), and the forgoing passage from his work on Dostoevsky (1984) all highlight how language is embodied by those that express it. Language constitutes the worlds that we experience with verisimilar objectivity and so speech genres are genres that constitute how we perceive and viscerally experience the world. Dialogue, therefore, necessarily involves what we take as an ontological given.

As such, where Matusov insists upon the freedom of dialogue, we are inclined to insist upon dialogue's ontological weight-dialogue that is about things that matter. The inhibitive force of adaptive technologies can undermine such weightiness, inclining students to remain alienated to the degree that there may well be nothing at stake for them, and they take no personal responsibility in their learning. In such cases, it is the educators who must bring something that matters for them as an ethical obligationperhaps a concern for their very selves or a respect for the material they teach. If students feel discomfort at the prospect of such an imposition, at being forced out of their alienated praxis, then this may well be a form of pedagogical 'violence' we affirm. Alexander Pope wrote in his Essay on Criticism that "[a] little learning is a dangerous thing; / Drink deep, or taste not the Pierian spring" (II. 215-6), and his sentiment is undeniably true. Likewise, in Daniel Deronda, George writes, "It is one of the secrets in that change of mental poise which has been fitly named conversion, that to many among us neither heaven nor earth has any revelation till some personality touches theirs with a peculiar influence, subduing them into receptiveness" (Bk. 5, Ch. 35). Such a sentiment obviously stands in stark opposition to the kind of education Matusov champions; we cite it here only to suggest that for all the freedom Matusov insists students should have, his insistence makes it impossible for them to experience what Eliot describes. If education is a dance (and a dance where one partner leads, at least for some of the time), our current pedagogical milieu, characterized by adaptive technologies, is like a brick wall standing between the partners in the middle of the dance floor, limiting their free movement.

\section{References}

Alter, A. (2018). Irresistible: The Rise of Addictive Technology and the Business of Keeping Us Hooked. New York: Penguin.

Bakhtin, M. (1984a). Problems of Dostoevsky's Poetics (C. Emerson, Trans.). Minneapolis: University of Minnesota Press.

Bakhtin, M. (1984b). Rabelais and His World (H. Iswolsky, Trans.). Bloomington: Indiana University Press.

Bakhtin, M. (1986). The problem of speech genres (V. McGhee, Trans.). In C. Emerson \& M. Holquist (Eds.), Speech Genres and Other Late Essays (pp. 60-102). Austin: University of Texas Press.

Bakhtin, M. (1990). Author and hero in aesthetic activity (V. Liapunov \& K. Brostrom, Trans.). In M. Holquist \& V. Liapunov (Eds.), Art and Answerability: Early Philosophical Essays. Austin: University of Texas Press. 
Bakhtin, M. (1993). Toward a Philosophy of the Act (V. Liapunov, Trans.). Austin: University of Texas Press.

Borgmann, A. (1992). Crossing the Postmodern Divide. Chicago: University of Chicago Press.

Carr, N. (2011). The Shallows: What the Internet Is Doing To Our Brains. New York: W. W. Norton Press.

Cresswell, J., \& Sullivan, P. (2019). Bakhtin's Chronotope, Eros, \& Discursive Psychology: Towards a Richer Interpretation of Experience. Qualitative Research in Psychology, 17(1), 121-142.

Eliot, G. (1986). Daniel Deronda. Toronto: Penguin.

Harris, T. (n.d.) https://www.tristanharris.com/resources.

Lanier, J. (2018). Ten Arguments for Deleting Your Social Media Accounts Right Now. New York: Henry Holt and Co.

Matusov, E. (2020). A Student's right to freedom of education. Dialogic Pedagogy: An International Online Journal, 8 (2020), SF1-SF28. doi:10.5195/dpj.2020.356

Plato. (1973). Phaedrus and Letters VII and VIII (W. Hamilton, Trans.) New York: Penguin.

Pope, A. (2018). Essay in Criticism. In Stephen Greenblatt \& James Noggle (Eds.), The Norton Anthology of English Literature, Tenth Edition. New York: Norton \& Company.

Postman, N. (1993). Technopoly. New York: Vintage.

Wu., T. (2017). The Attention Merchants: The Epic Scramble to Get Inside Our Heads. New York: Vintage Press.

\section{(cc) EY}

New articles in this journal are licensed under a Creative Commons Attribution 4.0 United States License.

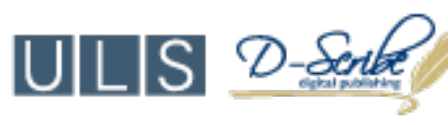

This journal is published by the University Library System, University of Pittsburgh as part of its D-Scribe Digital Publishing Program and is cosponsored by the University of Pittsburgh Press. 